\title{
The Development of a MOOCs Knowledge Repository System Using a Digital Knowledge Engineering Process to Enhance Digital Entrepreneurs' Competencies
}

\author{
https://doi.org/10.3991/ijep.v11i6.24409 \\ Nattaphol Thanachawengsakul ${ }^{1(\bowtie)}$, Panita Wannapiroon ${ }^{2}$ \\ ${ }^{1}$ Chandrakasem Rajabhat University, Bangkok, Thailand \\ ${ }^{2}$ King Mongkut University of Technology North Bangkok, Bangkok, Thailand \\ nattaphol.techandra.ac.th
}

\begin{abstract}
The objectives of this research were as follows: the development of a MOOCs knowledge repository system using a digital knowledge engineering process, and a competency assessment of digital entrepreneurs engaging in a MOOCs knowledge repository system using a digital knowledge engineering process. A total of 30 people were selected as a sampling group (purposive sampling) for this study, these included Small and Medium Enterprises (SMEs) in Bangkok with expertise in Human Performance Technology (HPT), as well as the MOOCs knowledge repository system. The mean, standard deviation, percentage, and a dependent sample t-test were used in the procedure for data analysis. The research findings suggested that: (1) the overall result concerning the development of a MOOCs knowledge repository system using a digital knowledge engineering process was at the highest level (Mean $=4.89$, S.D. $=0.31$ ), and (2) the overall result regarding the competencies of digital entrepreneurs after engaging in a MOOCs knowledge repository system using a digital knowledge engineering process passed the $80 \%$ rating, according to criteria. Moreover, learners who had undertaken activities through a MOOCs knowledge repository system using a digital knowledge engineering process improved their learning outcomes with a significance level of .05 based on the research hypothesis.
\end{abstract}

Keywords-MOOCs, knowledge repository system, digital knowledge engineering process, digital entrepreneurs' competencies

\section{Introduction}

The United Nations (UN) addresses three dimensions of sustainable development goals or SDGs; these are the economy, the environment and society. According to studies, the result showed that the progress towards environmental sustainability has been largely achieved while the goals of social and economic development were marked as displaying very slow progress, in particular, social sustainability in connection with reducing social inequalities and a more equal society such as income, education or resources. As a result, multiple changes have taken place in the roles of higher educational institutions in Thailand. Not only do universities have a role in preparing their graduates for the 
employment market, as a central part of their mission they are also committed to research for the public and private sectors. Additionally, the learning process should be undertaken to meet personal satisfaction (people), social relationships and human-environment relationships (planet), which are as important as prof-it-earning activities [1] consistent with the Policy and Strategy of Thailand HESI B.E. 2563-2570 (2020-2027); [2] as guidelines for the Ministry of Higher education, Science, Research and Innovation in order to move our nation forwards in accordance with National Strategy; [3] with the vision of "Thailand's 20-year National Strategy" to distribute economic and social growth center and create sustainability of environmental quality as well as strength of innovation so as to lead Thailand to become a developed country". The goals of national development are the development of human resources, educational institutions, research and the growth of innovative products towards an area-based development approach, as well as reducing inequalities. This accompanies systemic reform in higher education, science, research and innovation capacity, and is consistent with a master plan and government policy [4], which emphasizes the potential for upgrading in various dimensions for working age people. This includes specific skills, life skills, knowledge, and abilities that fit the labor market, as well as building multiple sources of revenue for long-term financial stability.

The development of digital technology is the consolidation of open education and Massive Open Online Courses (MOOCs). This involves online learning management including content, activities and open system evaluation and offers the opportunity for individuals to access educational materials without any restrictions. This type of online education is aimed at large-scale participation with free online courses and many free certificates. It also offers learners the option of paid certificates to earn academic credits through MOOCs [5]. Moreover, the developed system can be utilized as electronic knowledge repositories to help equalize access to knowledge, educational opportunities and lifelong learning [6]. The system includes sources of data collection, the systematic arrangement of groups or categories in digital and electronic files [7] with its attributes consisting of user management modules, knowledge management modules and report management modules [8]. There is also the application of a digital knowledge engineering learning process derived from the knowledge management of instructors and experts with skills and direct experience, in order to create best practices in terms of determining the source of a problem and finding an effective solution. Not only do learners leverage those skills for their professional life, but they also use digital technology for knowledge management. In addition, the developments include reskills and upskills comprising six steps: (1) knowledge creation, (2) knowledge storage, (3) knowledge acquisition, (4) knowledge access, (5) knowledge sharing and (6) knowledge application. These lead to the achievement of knowledge management in educational institutions and workplaces with the compilation of tacit/explicit knowledge that can easily be accessed by internal and external stakeholders [10].

In regard to direction setting for development of Thai education so as to move our nation forwards corresponding to National Strategy as well as the importance of using digital technology for online class management for reducing social inequalities and developing potential of working age people as mentioned above, the researchers came up with an idea of developing MOOCs knowledge repository system using a digital 
knowledge engineering process as well as assessing digital entrepreneurs' competencies engaging in the developed system. This development does not only help them to enhance their digital competencies, but it also creates spaces for knowledge sharing, reskilling and upskilling of knowledge, abilities, and the promotion of a positive mindset at work.

\section{$2 \quad$ Literature review}

The researchers conducted studies by gathering information from relevant research papers with the following details:

\subsection{Knowledge repository system}

A knowledge repository system is a collection of meaningful data and information within an organization that allows employees to bring all their knowledge together in one central location for easy, quick access and collaborative knowledge sharing. The system is compatible with all devices by connecting to the internet [6-7, 10]. It consists of three modules: the user management module, the knowledge management module, and the report management module [8-11]

\subsection{Massive open online course system (MOOCs)}

A MOOCs is an online learning platform delivering learning, teaching and assessment activities with easy access from anywhere at any time at the users' convenience. MOOCs are free online courses and anyone can enroll. They have the option of paid certificates, which are divided into two types. First, the cMOOC model (Connectivism MOOC) engages learners in social media activities to support their collaborative information discovery and sharing with unlimited participation. This method is mostly related to the reskills and upskills of knowledge. Second, the xMOOC model (Extended MOOC) focuses on the transmission of content that significantly limits learners' access to learning materials, as well as a limited communication space between teachers and learners. The xMOOC (Extended MOOC) comprises six elements: reading material, video lectures, discussion forums, quizzes, assignment and certificate [5, 12-15]. See Figure 1: 


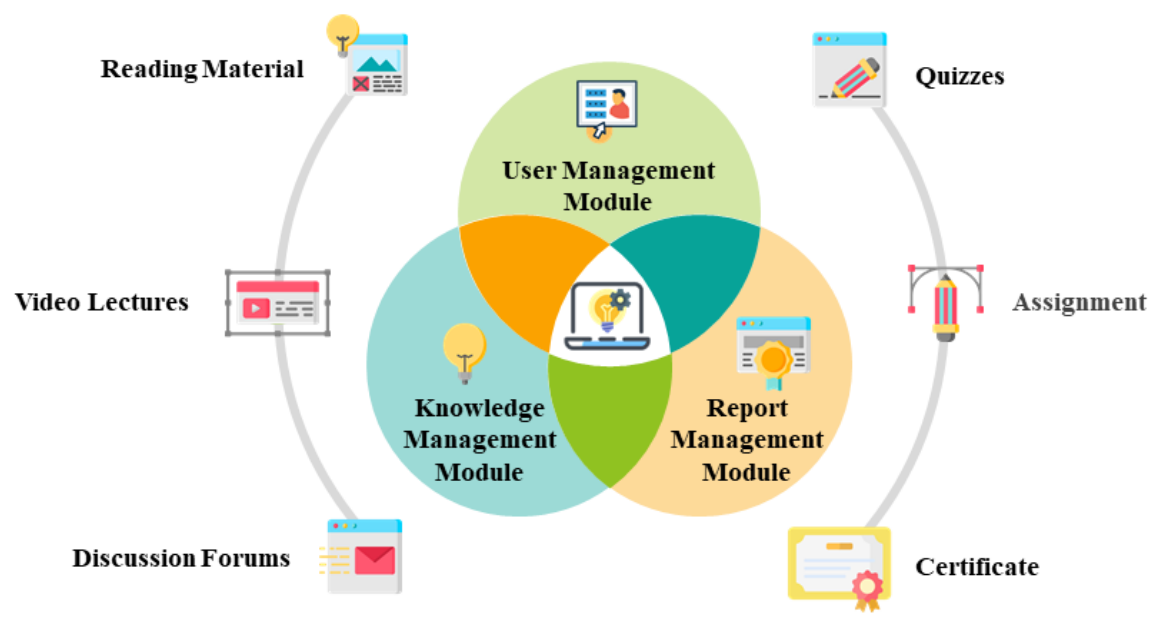

Massive Open Online Course System (MOOCs)

Fig. 1. Elements of Massive Open Online Course System (MOOCs)

\subsection{Knowledge engineering processes}

The process involves expert systems built by knowledge engineers/specialists enabling entrepreneurs access to complete their own studies, discover information and share knowledge. The process consists of six learning types: knowledge creation, knowledge storage, knowledge acquisition, knowledge access, knowledge sharing, knowledge application $[9,11,16]$. See Figure 2:

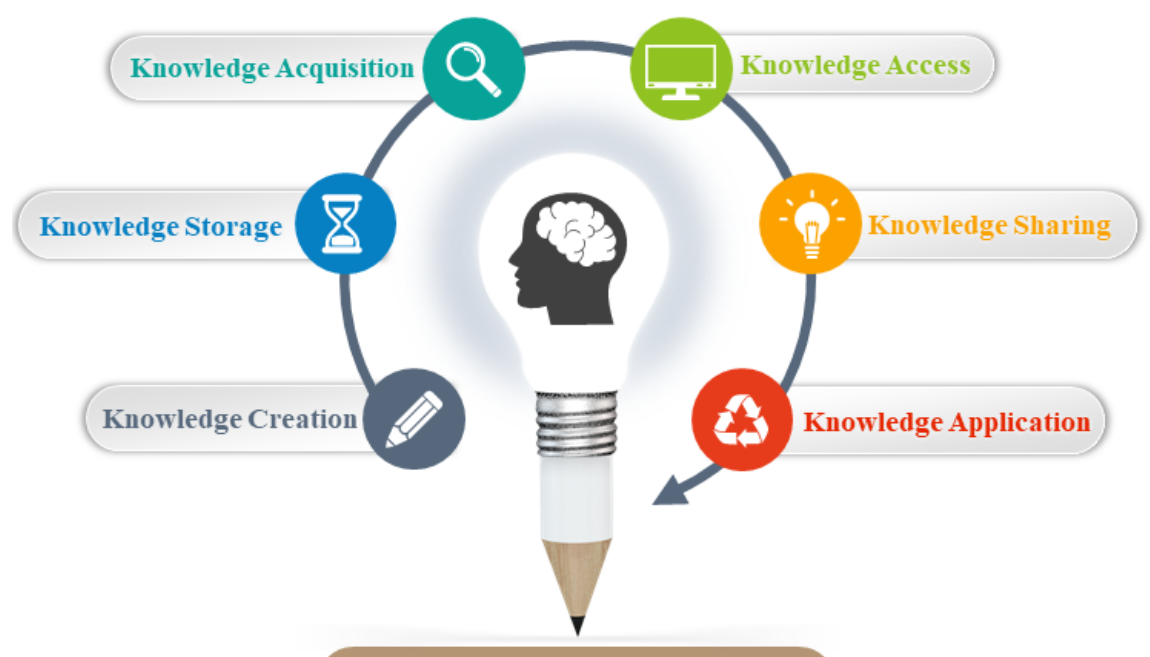

Knowledge Engineering Processes

Fig. 2. Knowledge Engineering Processes 


\subsection{Digital entrepreneurs' competencies}

Competencies are the utilization of knowledge, skills and attributes towards the application of technology in workplaces. A great entrepreneur 4.0 must not only have practical skills and knowledge of management, he/she must also have the ability to innovate scalable products or services that provide greater value, and adapt to constant changes in new technology. Therefore, digital entrepreneurs' competencies are management skills combined with digital literacy skills and are vital in developing their business [17-19]. To comply with Thailand's 4.0 concept, according to the 20-year national strategy "National Digital Economy and Society Development Plan and Policy", our research looks at development to help people increase their work efficiency. There were three levels of digital literacy skills: Level 1 - digital collaboration, Level 2 - digital workplace and Level 3 - digital access and awareness $[9,11]$.

Based upon the information gathered from documents and relevant research papers, the conceptual framework of this study is illustrated in Figure 3:

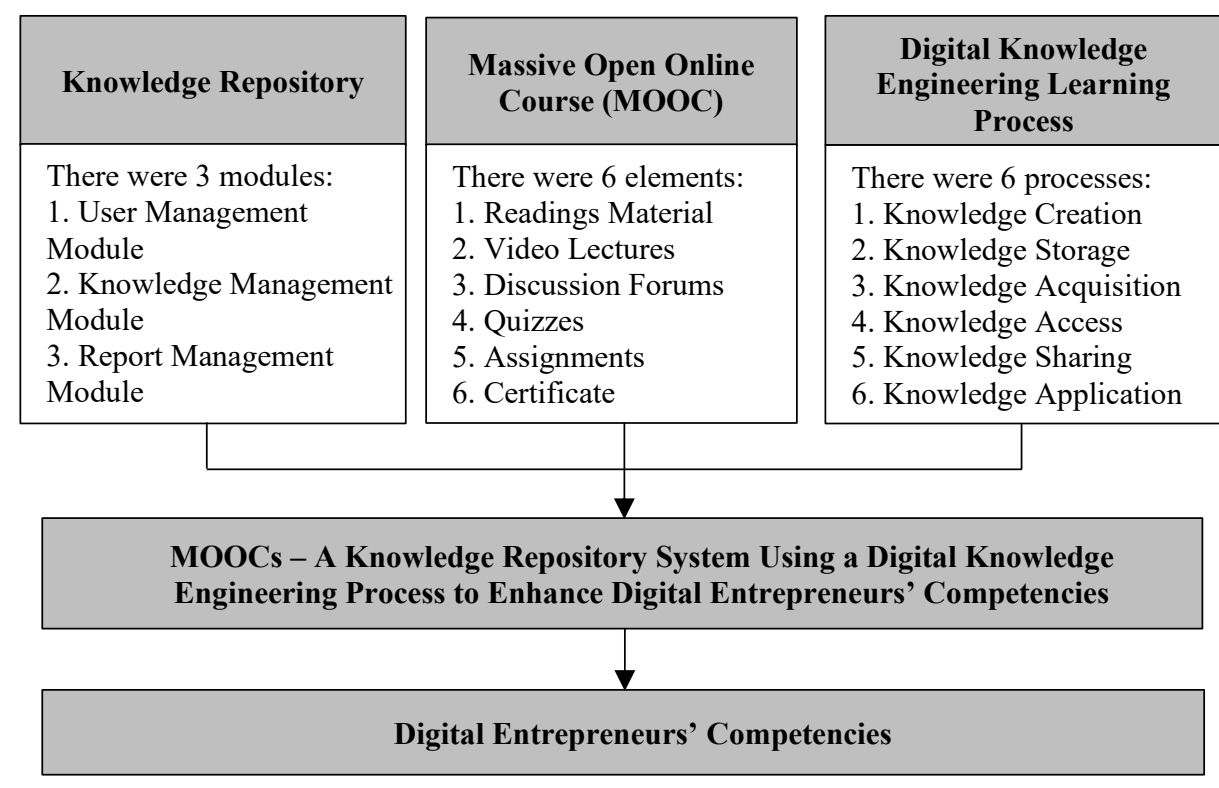

Fig. 3. Conceptual Framework for the Development of MOOCs

\section{$3 \quad$ Research objective}

1. To develop a MOOCs knowledge repository system using a digital knowledge engineering process to enhance digital entrepreneurs' competencies.

2. To assess the competencies of digital entrepreneurs engaging in a MOOCs knowledge repository system using a digital knowledge engineering process. 


\section{$4 \quad$ Research methodology}

The research methodology comprised two stages as follows:

\subsection{Development of a MOOCs knowledge repository system using a digital knowledge engineering process to enhance digital entrepreneurs' competencies}

The researchers used an Evolutionary Prototype in the development process. This was composed of five steps: develop abstract prototype, build prototype system, use prototype system, system adequate, and deliver system [20]. After the development process was carried out, the researchers proceeded to the next step to assess system efficiency. The assessment was performed by five experts with at least three years of experience in related fields, including three experts in information and communication technology and two experts in educational technology. A purposive sampling method was used.

\subsection{Assess the competencies of digital entrepreneurs engaging in a MOOCs knowledge repository system using a digital knowledge engineering process}

Regarding the assessment of digital entrepreneurs' competencies engaging in a digital knowledge engineering process, this included 30 Small and Medium Enterprises (SMEs) in Bangkok, with good skills in Human Performance Technology (HPT). Purposive sampling was used. The research process was carried out sequentially as follows:

1. Synthesis of documents, textbooks, academic articles, concepts and theories of relevant research papers from both domestic and international sources, with a content analysis for developing assessment criteria in connection with digital entrepreneurs' competencies.

2. Development of assessment criteria in connection with digital entrepreneurs' competencies according to Knowledge, Skills, and Attribute (KSA). The KSA process was composed of three parts: (1) Knowledge: multiple-choice questions for pre-and post-study module testing, (2) Skills: independent practice regarding being a digital entrepreneur, and (3) Attribute: desirable characteristics of self-awareness towards the application of technology in workplaces with four rating scales.

3. The researchers submitted the assessment criteria to five experts to determine an index of Item-Objective Congruence (IOC). It was found that the value of the knowledge part was equivalent to $0.60-1.00$, the value of the skill part was equivalent to $0.80-1.00$, and the value of the attribute part ranged between $0.80-1.00$.

4. The assessment criteria were applied to 30 people not in the sampling group as a tryout, and the results indicated that difficulty index (p) ranged between 0.27-0.80, the discrimination index $(\mathrm{r})$ ranged between $0.40-1.00$, and the reliability index $\left(\mathrm{r}_{\mathrm{tt}}\right)$ regarding multiple-choice ranged between $0.76-0.88$. 
5. The development of digital entrepreneurs' competencies participating in a MOOCs knowledge repository system using a digital knowledge engineering process based on Human Performance Technology. This included the HPT approach as well as analysis, summary and discussions about the assessment results of digital entrepreneurs' competencies with a minimum pass score of $80 \%$.

\section{$5 \quad$ Research findings}

5.1 Findings from development of a MOOCs knowledge repository system using a digital knowledge engineering process to enhance digital entrepreneurs' competencies

1. The results of develop abstract specification were as follows:

(a) The use case diagram of a MOOCs knowledge repository system using a knowledge engineering process is illustrated in Figure 4.

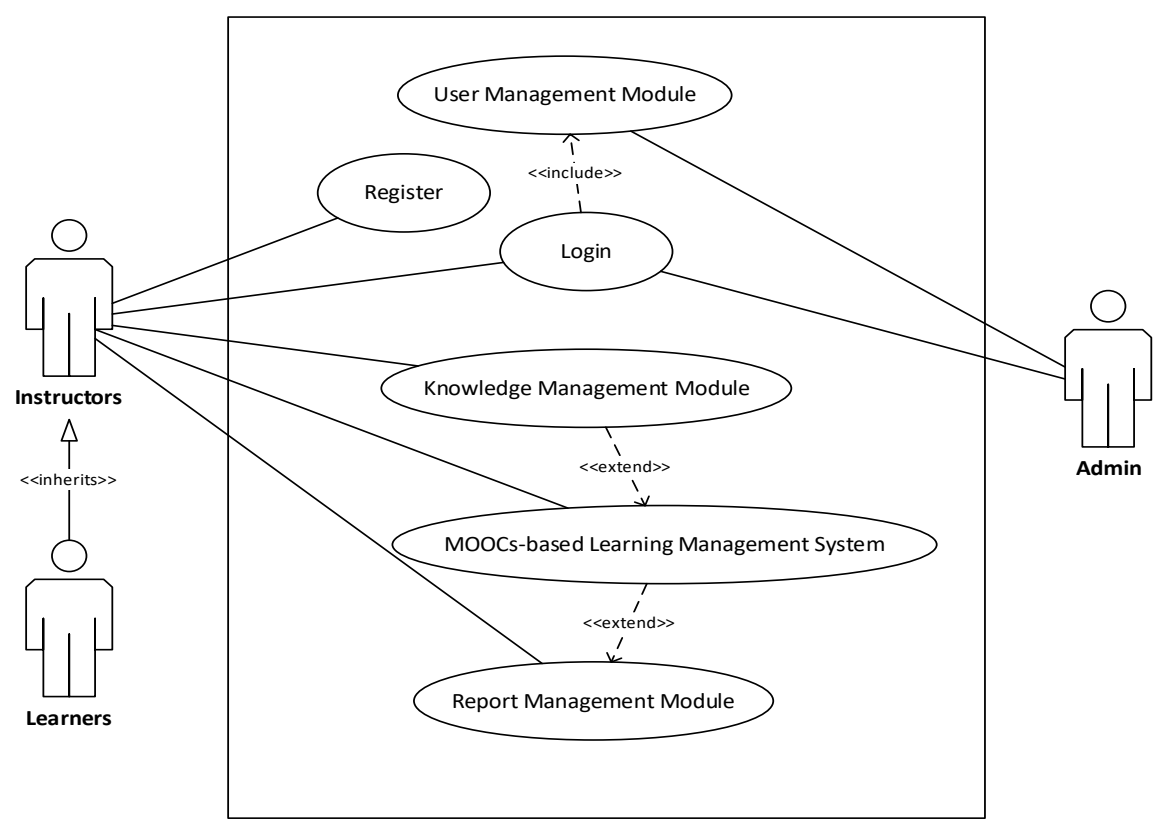

Fig. 4. Use Case Diagram

According to Figure 4, it described the features of use case description. See Table 1: 
Paper-The Development of a MOOCs Knowledge Repository System Using a Digital Knowledge...

Table 1. Use Case Description

\begin{tabular}{|c|c|c|}
\hline Stakeholder & Use Case Name & Normal Flow of Event \\
\hline Admin & $\begin{array}{l}\text { User Management } \\
\text { Module }\end{array}$ & $\begin{array}{l}\text { Management of user data including } \\
\text { adding, editing, deleting, revising, and searching, as well as con- } \\
\text { figuring user access control and permissions }\end{array}$ \\
\hline $\begin{array}{l}\text { Admin } \\
\text { Instructors } \\
\text { Learners }\end{array}$ & Login & $\begin{array}{l}\text { Access authentication by logging in with username and pass- } \\
\text { word }\end{array}$ \\
\hline $\begin{array}{l}\text { Instructors } \\
\text { Learners }\end{array}$ & Register & Creating a new user account for system access \\
\hline $\begin{array}{l}\text { Instructors } \\
\text { Learners }\end{array}$ & $\begin{array}{c}\text { Knowledge } \\
\text { Management Module }\end{array}$ & $\begin{array}{l}\text { - Instructors organized data management } \\
\text { - Learners assisted in creating knowledge }\end{array}$ \\
\hline $\begin{array}{l}\text { Instructors } \\
\text { Learners }\end{array}$ & $\begin{array}{l}\text { MOOCs-based Learning } \\
\text { Management system }\end{array}$ & $\begin{array}{l}\text { - Instructors handled course management relating to digital en- } \\
\text { trepreneurship } \\
\text { - Instructors managed content regarding digital entrepreneurship } \\
\text { by using reading materials and video lecture tools } \\
\text { - Communication between instructors and learners through dis- } \\
\text { cussion forums } \\
\text { - Instructors used quiz tool to create assessments for learning } \\
\text { - Instructors provided assignment instructions to learners } \\
\text { through the assignment tools } \\
\text { - Instructors issued a certificate to those who enrolled in a } \\
\text { course, completed all assignments and passed the test regarding } \\
\text { digital entrepreneurship } \\
\text { - Learners learned digital entrepreneurship lesson plans } \\
\end{array}$ \\
\hline Instructors & $\begin{array}{l}\text { Report Management } \\
\text { Module }\end{array}$ & $\begin{array}{l}\text { Instructors reviewed learners' achievement reports in CSV for- } \\
\text { mat obtained from the tests through a MOOCs-based learning } \\
\text { management system }\end{array}$ \\
\hline
\end{tabular}

(b) The system design architecture of a MOOCs knowledge repository system using a digital knowledge engineering process is illustrated in Figure 5:

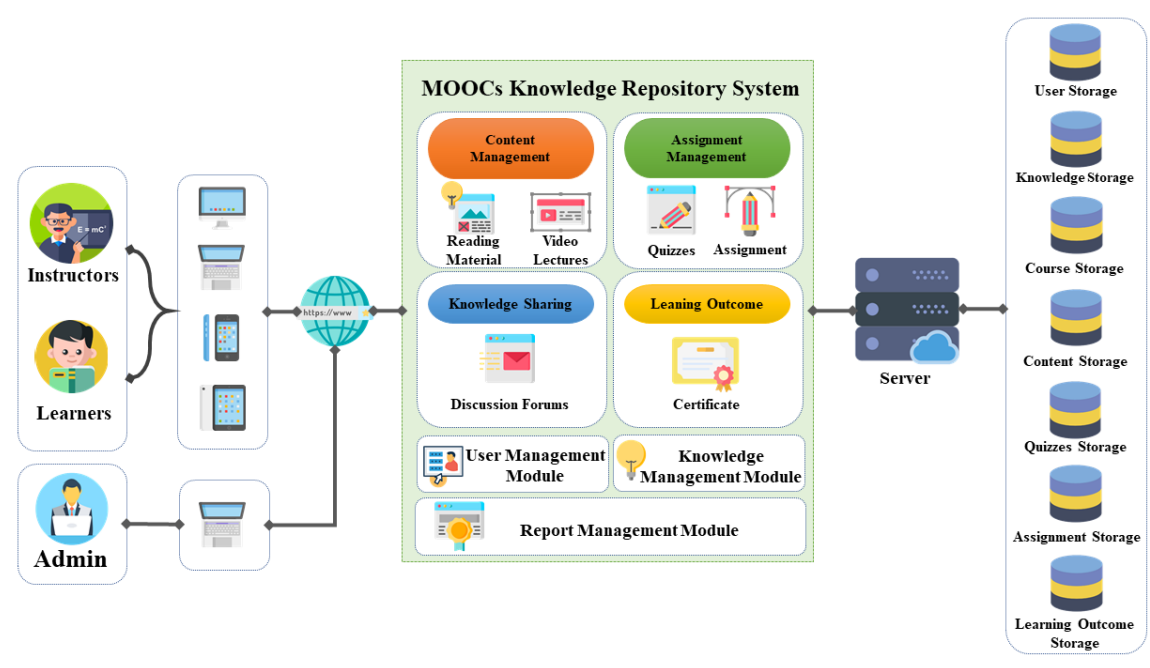

Fig. 5. The system design architecture of a MOOCs knowledge repository system using a digital knowledge engineering process 
Paper-The Development of a MOOCs Knowledge Repository System Using a Digital Knowledge...

Figure 5 describes a MOOCs knowledge repository system using a digital knowledge engineering process shown in Table 2:

Table 2. Description of the MOOCs knowledge repository system using a digital knowledge engineering process.

\begin{tabular}{|l|l|}
\hline \multicolumn{1}{|c|}{ Elements } & \multicolumn{1}{c|}{ Description } \\
\hline Part I: User & $\begin{array}{l}\text { 1. Admin: responsible for access control, safeguarding and maintaining data in } \\
\text { back-office forms as well as user management to access the system through the } \\
\text { user management module. } \\
\text { 2. Instructors and Learners: participation in learning activities and collaborative } \\
\text { learning in relation to the content of the digital knowledge engineering learning } \\
\text { process through the MOOCs knowledge repository system. }\end{array}$ \\
\hline Part II: Device Services & $\begin{array}{l}\text { Accessing data service through a web browser e.g. Google Chrome and Internet } \\
\text { Explorer by connecting through a domain name server of a MOOCs knowledge } \\
\text { repository system and other compatible devices e.g. personal computer, laptop, } \\
\text { tablet and smartphone. }\end{array}$ \\
\hline $\begin{array}{l}\text { Part III: MOOCs } \\
\text { Knowledge Repository } \\
\text { System }\end{array}$ & $\begin{array}{l}\text { Software developed for learning enhancement to enable instructors and learners } \\
\text { to work collaboratively based on a digital knowledge engineering learning pro- } \\
\text { cess consisting of two parts: knowledge repository module and massive open } \\
\text { online course system (MOOCs). }\end{array}$ \\
\hline $\begin{array}{l}\text { Part IV: Storage } \\
\text { Services }\end{array}$ & $\begin{array}{l}\text { The storage services were provided by a MOOCs knowledge repository system } \\
\text { in a client-server model alongside a MySQL database management system. The } \\
\text { database system comprised 7 parts including user storage, knowledge storage, } \\
\text { course storage, content storage, quiz storage, assignment storage and learning } \\
\text { outcome storage. }\end{array}$ \\
\hline
\end{tabular}

The results of the architecture development of a MOOCs knowledge repository system using a digital knowledge engineering process are illustrated in Table 3 :

Table 3. The findings from architecture design of the MOOCs knowledge repository system using a digital knowledge engineering process suitability assessment.

\begin{tabular}{|l|c|c|c|}
\hline \multirow{2}{*}{ Point of Assessment } & \multicolumn{3}{|c|}{ Level of Opinions } \\
\cline { 2 - 4 } & $\bar{X}$ & S.D. & Rating Scales \\
\hline Part I: User & 5.00 & 0.00 & Highest \\
Part II: Device Services & 4.80 & 0.42 & Highest \\
Part III: MOOC Knowledge Repository System & 4.96 & 0.21 & Highest \\
Part IV: Storage Services & 4.97 & 0.17 & Highest \\
\hline Mean & 4.95 & 0.21 & Highest \\
\hline
\end{tabular}

The results in Table 3 indicate that the architecture design of the MOOCs knowledge repository system using a digital knowledge engineering process was at the highest level $($ Mean $=4.95$, S.D. $=0.21)$. However, when the assessment for each section is arranged in descending order, it can be seen that 'Part I: User' comes out highest (Mean $=5.00$, S.D. $=0.00)$ followed by 'Part IV: Storage Services' $($ Mean = 4.97, S.D. =0.17), 'Part III: MOOC Knowledge Repository System' (Mean = 4.96, S.D. =0.21) and 'Part II: Device Services' (Mean $=4.80$, S.D. $=0.42)$. 
2. The Results of the Build Prototype System: The MOOCs knowledge repository system using a digital knowledge engineering process was developed with software engineering and a learning management system accessible via a web browser http://www.moocrepositiry.com, the user guidelines are provided in Figure 6:

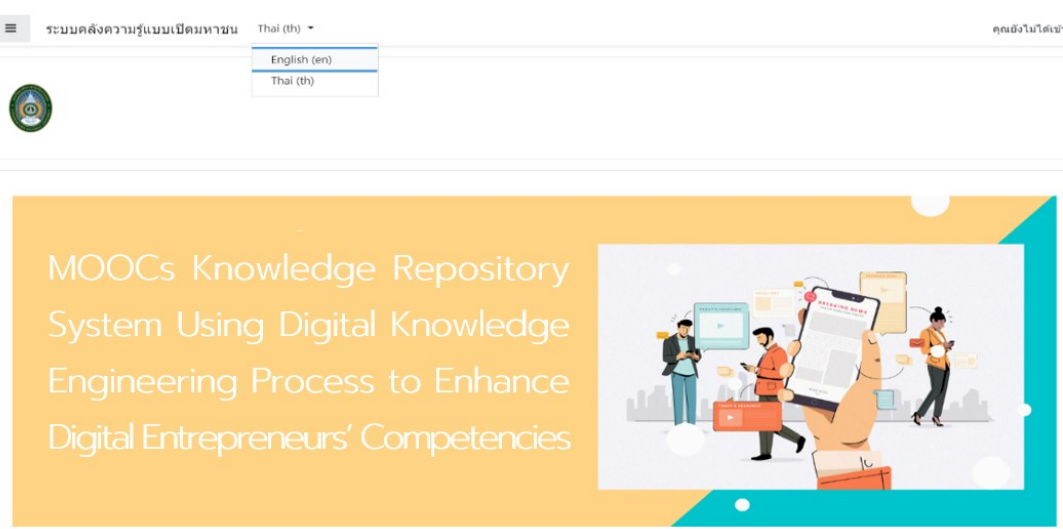

Fig. 6. MOOCs knowledge repository system at Home Page

As shown in Figure 6, two languages are available in the MOOCs knowledge repository system at Home Page Thai and English with multi-device compatibility for personal computer, laptop and smartphone. Moreover, the system was compatible. The site map of the MOOCs knowledge repository system is illustrated in Figure 7:

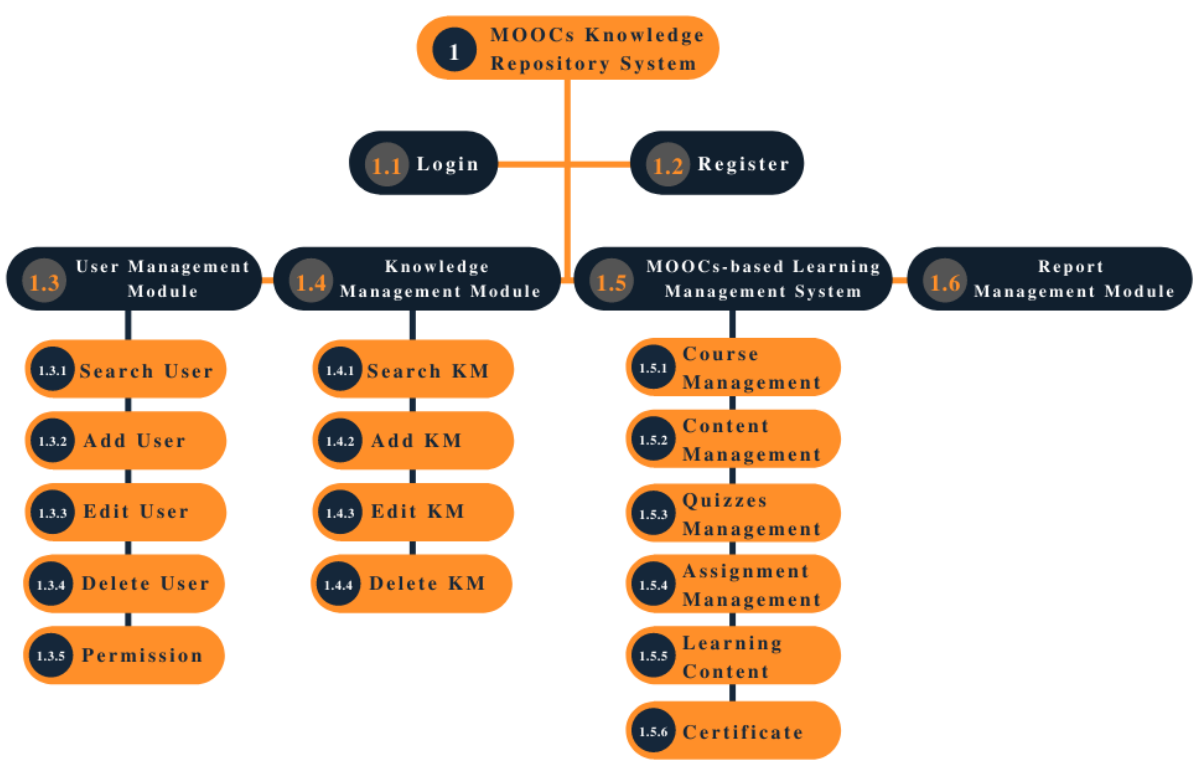

Fig. 7. Site Map of the MOOCs knowledge repository system 
According to Figure 7, the home screen on the system is composed of six parts as follows:

- Part I: Login - access authentication by logging in with username and password.

- Part II: Register - member registration for system access.

- Part III: User Management Module - management of user data including adding, deleting, revising, and searching as well as configuring user access control and permissions.

- Part IV: Knowledge Management Module - knowledge management concerning entrepreneurship including adding, deleting, revising, and searching.

- Part V: MOOCs-based Learning Management System - course management, content management, quiz management, assignment management, learning content and certificate.

- Part VI: Report Management Module - producing a learners' achievement report where instructors reviewed learners' achievement reports in CSV format obtained from the tests through a MOOCs-based learning management system.

3. The results of Use Prototype System: The MOOCs knowledge repository system was tested by five experts in two related fields including three experts in information and communication technology and two experts in educational technology. The software testing involved the execution of the system to evaluate course management, course instructional design, course development, course implementation and course evaluation.

4. The results of System Adequate: The results regarding the efficiency of the MOOCs knowledge repository system using a digital knowledge engineering process assessed by the experts are illustrated in Table 4:

Table 4. Efficiency of the MOOCs knowledge repository system using a digital knowledge engineering process

\begin{tabular}{|l|c|c|c|}
\hline \multirow{2}{*}{ Point of Assessment } & \multicolumn{3}{|c|}{ Efficiency Levels } \\
\cline { 2 - 4 } & $\bar{X}$ & S.D. & Rating Scales \\
\hline 1. Course Management & 4.87 & 0.35 & Highest \\
2. Course Instructional Design & 4.91 & 0.29 & Highest \\
3. Course Development & 4.91 & 0.28 & Highest \\
4. Course Implementation & 4.91 & 0.28 & Highest \\
5. Course Evaluation & 4.80 & 0.41 & Highest \\
\hline Mean & 4.89 & 0.31 & Highest \\
\hline
\end{tabular}

Table 4 reveals that the efficiency of the MOOCs knowledge repository system using a digital knowledge engineering process was at the highest level (Mean $=4.89$, S.D. $=$ 0.31 ). However, when each item was arranged in descending order, efficiency of course instructional design, course development and course implementation were at the highest level $($ Mean $=4.91$, S.D. $=0.29,0.28)$ followed by course management $($ Mean $=$ 4.87 , S.D. $=0.35)$, and course evaluation $($ Mean $=4.80$, S.D. $=0.41)$, respectively. 
5. The results of Deliver System: To evaluate digital entrepreneur competencies, the system was reviewed by the experts and assessment criteria were applied to Small and Medium Enterprises (SMEs) in Bangkok. The results are discussed below in next findings.

\subsection{Findings from Assess the competencies of digital entrepreneurs engaging in a MOOCs knowledge repository system using a digital knowledge engineering process}

The results of digital entrepreneur competencies were assessed based on knowledge, skills, and attribute (KSA). The KSA process comprised three parts: knowledge, skills and attribute and completed with the knowledge engineering process as follows:

1. The assessment results of digital entrepreneur competencies Level 1 - digital collaboration: the overall score of the 30 participants ranged between $80-92$, equivalent to $86.02-98.92 \%$, which a minimum passed score the $80 \%$ according to the criteria. Table 5 shows the results of learners' learning achievement before and after utilizing a MOOCs knowledge repository system with a digital knowledge engineering process. A dependent sample t-test method was employed.

Table 5. Comparison of learners' learning achievement concerning pre-post study Level 1 Digital Collaboration

\begin{tabular}{|l|c|c|c|c|c|}
\hline \multicolumn{1}{|c|}{ Test } & $\mathbf{~ N}$ & $\overline{\mathbf{X}}$ & S. D. & t & Sig. \\
\cline { 1 - 4 } Pre-study & 30 & 13.10 & 3.97 & \multirow{2}{*}{19.54} & $.000^{*}$ \\
\hline Post-study & 30 & 26.53 & 2.19 & & \\
\hline
\end{tabular}

* Significance level of .05

The results in Table 5 indicate that learners engaging in a MOOCs knowledge repository system using a digital knowledge engineering process can improve their learning outcome, Level 1 - digital collaboration, with a significance level of .05 based on the research hypothesis.

2. The assessment results of digital entrepreneur competencies Level 2 - digital workplace: the overall score of 30 participants ranged between 116-135, equivalent to $80.56-93.75 \%$, which a minimum passed score the $80 \%$ according to the criteria. Table 6 shows the results of learners' learning achievement before and after utilizing MOOCs knowledge repository system with a digital knowledge engineering process. A dependent sample t-test method was employed.

Table 6. Comparison of learners' learning achievement concerning pre-post study Level 2 -

$$
\text { Digital Workplace }
$$

\begin{tabular}{|l|c|c|c|c|c|}
\hline \multicolumn{1}{|c|}{ Test } & N & $\overline{\mathbf{X}}$ & S. D. & t & Sig. \\
\hline Pre-study & 30 & 15.13 & 4.04 & \multirow{2}{*}{15.73} & $.000^{*}$ \\
\hline Post-study & 30 & 24.17 & 2.28 & & \\
\hline
\end{tabular}

* Significance level of .05 
The results shown in Table 6 indicate that learners engaging in a MOOCs knowledge repository system using a digital knowledge engineering process can improve their learning outcome, Level 2 - digital workplace, with a significance level of .05 based on the research hypothesis.

3. The assessment results of digital entrepreneur competencies Level 3 - digital access and awareness: the overall score of 30 participants ranged between 104-123, equivalent to $80.62-95.35 \%$, which a minimum passed score the $80 \%$ according to the criteria. Table 7 shows the results of learners' learning achievement before and after utilizing a MOOCs knowledge repository system with a digital knowledge engineering process. A dependent sample t-test method was employed.

Table 7. Comparison of learners' learning achievement concerning pre-post study Level 3 Digital Access and Awareness

\begin{tabular}{|l|c|c|c|c|c|}
\hline Test & $\mathbf{~ N}$ & $\overline{\mathbf{X}}$ & $\mathbf{S . ~ D . ~}$ & $\mathbf{t}$ & Sig. \\
\hline Pre-study & 30 & 13.73 & 2.42 & \multirow{2}{*}{13.79} & \multirow{2}{*}{$.000^{*}$} \\
\hline Post-study & 30 & 22.83 & 2.37 & & \\
\hline
\end{tabular}

* Significance level of .05

The results shown in Table 7 indicate that learners engaging in a MOOCs knowledge repository system using a digital knowledge engineering process can improve their learning outcome, Level 3 - digital access and awareness, with a significance level of .05 based on the research hypothesis.

\section{Conclusion}

1. With regard to the development of a MOOCs knowledge repository system using a digital knowledge engineering process to enhance digital entrepreneurs' competencies with an evolutionary prototype model [20], the overall result of system efficiency was at the highest level $($ Mean $=4.89$, S.D. $=0.31)$. This study used several resources such as documents, textbooks, academic articles and relevant research papers from both domestic and international sources. Content analysis was used to develop the conceptual framework of a MOOCs knowledge repository, and used a knowledge engineering process to enhance digital entrepreneur competencies [9]. It also developed a learning ecosystem that applied digital knowledge engineering through the MOOCs knowledge repository system [11] to describe the learning environment, and the roles of instructors and learners to enhance digital entrepreneur competencies. The research findings suggested that the MOOCs knowledge repository developed contained the following:

- A digital engineering process consisting of six steps: (1) knowledge creation, (2) knowledge storage, (3) knowledge acquisition, (4) knowledge access, (5) knowledge sharing, and (6) knowledge application. 
- A knowledge repository system consisting of three subsystems: (1) a user management system, (2) a knowledge management system, and (3) a report management system.

- A MOOCs learning management system comprising six elements: (1) reading materials, (2) video lectures, (3) discussion forums, (4) quizzes, (5) assignment, and (6) certificate.

- Digital entrepreneur competencies consisted of three levels: (1) digital collaboration, (2) digital workplace, and (3) digital access and awareness.

This study was consistent with the research papers of Marina Zotova, Tetiana Likhouzova, Liliya Shegai, and Elena Korobeynikova [14], Dilrukshi Gamage, Indika Perera, and Shantha Fernando [21] and Charochinee Chaimin [22]. The MOOCs knowledge repository that was developed can be used for data collection from the sampling group to assess digital entrepreneurs' competencies.

2. With respect to the competencies of digital entrepreneurs after engaging in a MOOCs knowledge repository system using a digital knowledge engineering process, the study revealed that the learners passed all three levels of digital entrepreneur competencies scoring over $80 \%$, and they can improve their learning outcome with a significance level of .05 . In this study, the researchers applied a MOOCs knowledge repository system to learners' learning development They also assessed digital entrepreneurs' competencies according to the concepts of the Thailand Professional Qualification Institute (Public Organization) [23], the IC3 Digital Literacy Certificate [24], the International Computer Driving License [25] and Microsoft Office Specialist [26]. Furthermore, the researchers had a systematic set of steps to identify behavioral indicators and item specification in line with the assessment criteria. The assessment criteria were also submitted to experts to determine an index of ItemObjective Congruence (IOC). This was applied to 30 people not in the sampling group as a tryout, and the results indicated that difficulty index (p), discrimination index (r) and reliability index $\left(\mathrm{r}_{\mathrm{tt}}\right)$. The results revealed that the development of assessment criteria can be effectively used for the assessment of digital entrepreneurs' competencies. For further research, learning by using a MOOCs knowledge repository system with a digital knowledge engineering process should include Small and Medium Enterprises (SMEs) other than those listed in this study. Additionally, digital technology or digital techniques should be applied to MOOCs knowledge repository system e.g., decision support system, machine learning and hybrid learning system.

\section{Conflict of interest and research ethics}

The author declares no conflict of interest. With regards to ethics, the researchers were allowed to conduct the study according to the announcement of the Chandrakasem Rajabhat University: No. 008/2563 on June 8, 2020. 


\section{Acknowledgement}

I would like to express my sincere gratitude to Chandrakasem Rajabhat University for your generous offer of research funding under Award No. 2/2562, Fiscal Year 2019, and appreciate for the owners of research articles, documentary, textbooks, and all sources of information. Without their valuable opinions and ideas, the research would not have been accomplished.

\section{$9 \quad$ References}

[1] Chulalongkorn University, "The Changing Roles of Universities to Create Sustainable Society," Chulalongkorn University, October 29, 2018. [Online]. Available: https://www. chula.ac.th/cuinside/13996. [Accessed May 2, 2021].

[2] Office of National Higher Education Science Research and Innovation Policy Council and Thailand Science Research and Innovation, Policy and Strategy of Thailand HESI (20202027), Bangkok: Ministry of Higher Education, Science, Research and Innovation, 2019.

[3] The Prime Minister's Office, National Strategy (2018-2037), Bangkok: The Prime Minister's Office, 2018. https://doi.org/10.1515/9781400878260-002

[4] The Prime Minister's Office, Master Plan under National Strategy (2018-2037), Bangkok: The Prime Minister's Office, 2019. https://doi.org/10.1515/9781400878260-002

[5] P. Suwannatthachote and S. Sophonhiranrak, Standards and Guidelines for Quality Assurance and Accreditation of MOOCs, Bangkok: Thailand Cyber University Project The Office of the Higher Education Commission, 2017.

[6] A. Theeraroungchaisri, "MOOC and Future of Thai Education in Digital Age," nectec, October 21, 2018. [Online]. Available: https://www.nectec.or.th. [Accessed May 2, 2021].

[7] Training Industry, "Knowledge Repositories," Training Industry, July 6, 2019. [Online]. Available: https://trainingindustry.com. [Accessed May 2, 2021].

[8] F. B. Fabio and D.d. S.C. Veruska, "Ipea's Knowledge Repository," $16^{\text {th }}$ European Conference on Knowledge Management at Udine, Italy, pp. 1-11, 2015.

[9] N. Thanachawengsakul, "A Conceptual Framework for the Development of a MOOCsBased Knowledge Repository to Enhance Digital Entrepreneurs' Competencies," International Journal of Information and Education Technology (IJIET), vol. 10, no. 5, pp. 346350, 2020. https://doi.org/10.18178/ijiet.2020.10.5.1387

[10] P. Kokaew, "Development of Digital Repository of The Faculty of Veterinary Science, Mahidol University," M. S. thesis, Silpakorn University, Nakhon Pathom, Thailand, 2016. https://doi.org/10.12980/apitd.7.2017d7-85

[11] N. Thanachawengsakul and P. Wannapiroon, "Development of a Learning Ecosystem Using Digital Knowledge Engineering Through MOOCs Knowledge Repository System," International Journal of Engineering Pedagogy (iJEP), vol. 11, no. 1, pp. 35-48, 2021. https://doi.org/ 10.3991/ijep.v11i1.15011

[12] Thailand Cyber University Project, Guidelines for Massive Open Online Course (MOOC) teaching readiness in Higher Education Institutes, Bangkok: Office of the Higher Education Commission, 2018.

[13] DSTI, Working Party on Measurement and Analysis of the Digital Economy: Skills for a Digital World, Mexico: OECD publications, 2016. 
[14] M. Zotova, T. Likhouzova, L. Shegai, and E. Korobeynikova, "The Use of MOOCS in Online Engineering Education," International Journal of Engineering Pedagogy (iJEP), vol. 11, no. 3, pp. 157-173, 2021. https://doi.org/10.3991/ijep.v11i3.20411

[15] M. Zappatore, "The Immersive Workbench for Engineering Educators: (Re) Thinking Collaborative and Distance Learning Platforms as Technological Enablers," International Journal of Engineering Pedagogy (iJEP), vol. 11, no. 4, pp. 4-6, 2021. https://doi.org/10.3991/ijep.v11i4.25297

[16] N. Thanachawengsakul, P. Wannapiroon, and P. Nilssok, "Synthesis of Digital Knowledge Engineering Repository Management system," International Journal of e-Education, eBusiness, e-Management and e-Learning (IJEEEE), vol. 9, no. 4, pp. 348-356, 2018. https://doi.org/10.17706/ijeeee.2019.9.4.348-356.

[17] M. Bacigalupo, P. Kampylis, Y. Punie, and G. Van den Brande, EntreComp: The Entrepreneurship Competence Framework, Spain: European Union, 2016.

[18] V. Bortkeviciene, "The Importance of entrepreneurial competence in Activities," Holistins Mokymasis and Holistic Learning, no. 4, pp. 81-91.

[19] A. Komarkova, D. Gagliardi, J. Conrads, and A. Collado, Entrepreneurship competence: An overview of Existing Concepts, Policies and Initiatives, Spain: European Union, 2015.

[20] Y. Limpiyakorn, Process Improvement Software, Bangkok: Chulalongkorn University, 2012.

[21] D. Gamage, I. Perera, andS. Fernando, "MOOCs Lack Interactivity and Collaborativeness: Evaluating MOOC Platforms," International Journal of Engineering Pedagogy (iJEP), vol. 10, no. 2, pp. 94-111, 2020. https://doi.org/10.3991/ijep.v10i2.11886

[22] C. Chaimin, "MOOC: Life Long Learning in the $21^{\text {st }}$ century," Journal of Humanities and Social Sciences, vol. 1, no. 1, pp. 46-70, 2019.

[23] TPQI, “Digital Literacy," TPQI, July, 2019. [Online]. Available: https://www.tpqi.go.th. [Accessed May 2, 2021].

[24] IC3, “IC3 Digital Literacy Certification,” IC3, July 13, 2019. [Online]. Available: https://certiport.pearsonvue.com. [Accessed May 2, 2021].

[25] ICDL, "The International Computer Driving License," ICDL, July 13, 2019. [Online]. Available: https://www.icdlasia.org. [Accessed May 2, 2021].

[26] MOS, "Microsoft Office Specialist (MOS)," MOS, July 13, 2019. [Online]. Available: https://www.arit.co.th. [Accessed May 2, 2021].

\section{Authors}

Nattaphol Thanachawengsakul is currently working as an instructor for bachelor of education program in computer, Faculty of Science, Chandrakasem Rajabhat University, Bangkok, Thailand. He has expertise in system analysis and design, digital content, information and communication technology for education, digital knowledge engineering, knowledge management in education institutions, measurement and evaluation in education, educational management with the use of information and communication technology and research of information and communication technology for education. His Doctor of Philosophy in Information and Communication Technology for Education was awarded a by King Mongkut's University of Technology North Bangkok (KMUTNB), Thailand.

Panita Wannapiroon is an associate professor at Division of Information and Communication Technology for Education, Faculty of Technical Education, King Mongkut's University of Technology North Bangkok (KMUTNB), Thailand. She has 
Paper - The Development of a MOOCs Knowledge Repository System Using a Digital Knowledge...

experience in many positions such as the director at Innovation and Technology Management Research Center, as assistant director of Online Learning Research Center, as assistant director of Vocational Education Technology Research Center, and an assistant director of Information and Communication Technology in Education Research Center (email: panita.w@fte.kmutnb.ac.th).

Article submitted 2021-05-31. Resubmitted 2021-09-12. Final acceptance 2021-10-05. Final version published as submitted by the authors. 